\title{
THERMOELASTIC INVESTIGATION OF DAMAGE EVOLUTION IN SMALL STAINLESS STEEL PIPEWORK
}

\author{
S. Quinn ${ }^{1, \mathrm{a}}$, P.J. Tatum ${ }^{2, \mathrm{~b}}$, J.M. Dulieu-Barton ${ }^{1, \mathrm{c}}$ and J. Eaton-Evans ${ }^{1, \mathrm{~d}}$ \\ ${ }^{1}$ School of Engineering Sciences \\ University of Southampton \\ Highfield \\ ${ }^{2}$ AWE plc \\ Reading \\ Southampton \\ Berkshire \\ SO17 1BJ \\ RG7 4PR \\ UK \\ UK \\ as.quinn@soton.ac.uk, btatum@awe.co.uk, cjanice@ship.soton.ac.uk, djeee103@soton.ac.uk
}

\section{Summary}

In this work thermoelastic stress analysis (TSA) is used to reveal information about the damage evolution process in small stainless steel pipework. TSA is a well-established stress analysis technique, see Dulieu-Barton and Stanley [1], based on the measurement of the small temperature change developed in a material as a result of elastic cyclic loading. The temperature change is directly proportional to the change in the sum of the principal surface stresses $\left(\Delta\left(\sigma_{1}+\right.\right.$ $\left.\sigma_{2}\right)$ ), see Stanley and Chan [2]. This relationship is usually sufficient for linear elastic, homogeneous problems, where the assumption is made that the temperature change is adiabatic.

However, TSA has also been successfully used to detect and evaluate subsurface damage and flaws by Sathon and Dulieu-Barton [3], by considering information from thermoelastic data for a range of loading frequencies. In this work damage, in the form of semi-circular notches, was introduced into a flat aluminium plate and thermoelastic data was gathered from the undamaged side of the plate. Damage increases the stress gradient in a component and can lead to nonadiabatic behaviour. This non-adiabatic behaviour can be used to reveal the sub surface stresses, by considering the phase information from the thermoelastic signal [3]. In Ref. [3] different damage severities were considered and flaws only a quarter the way through the thickness of the $5.3 \mathrm{~mm}$ thick plate were revealed by the thermoelastic data. This illustrates the promise of TSA to assess subsurface damage and in the current work this is tested for a real industrial problem.

The pipes under consideration were of cylindrical section and have an outside diameter of $3.175 \mathrm{~mm}$ and an inside diameter of $1.753 \mathrm{~mm}$, i.e. a wall thickness of $0.711 \mathrm{~mm}$. On assembly in service the material, 304L quarter hardened stainless steel (UNS S30400), is cold worked by bending around a former. During the product life cycle, maintenance is performed that requires the pipes to be straightened and then bent back to the original shape. To model this operation six specimens, with different deformation histories, of the stainless steel cylindrical section have been deformed to shape around a former identical to that used in the assembly process. The bent shape is illustrated in Fig. 1, along with the loading arrangement. The specimens were loaded in bending by applying cyclic compression through the loading blocks shown in Fig. 1. Only one loading block is shown, for clarity, the details are mirrored about the horizontal centreline. A 
loading pip was machined in the centre of two flat loading platens and the specimen was loaded in compression through the use of two $5 \mathrm{~mm}$ diameter ball bearings.
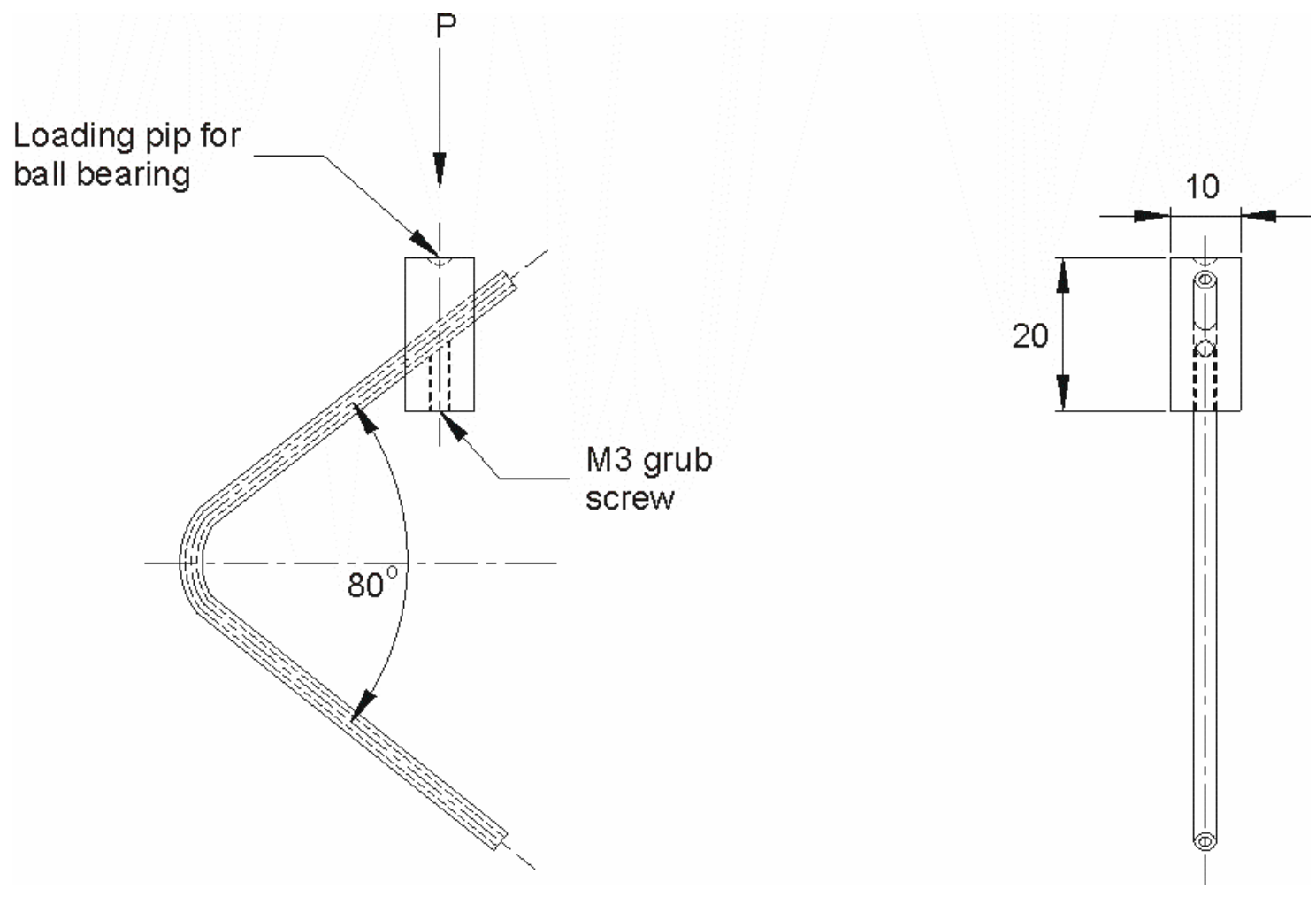

FIGURE 1. Schematic diagram of the loading arrangement for the deformed pipe tests.

Previous work, Quinn et. al. [4], identified that failure of these pipe is instigated at the inside of the outer surface of the pipe. This is obviously not optically accessible and so the techniques developed in [3] have been adopted to reveal information about the damage evolution process at this inner surface under fatigue conditions. The most damaged pipe, subjected to 6 bending and straightening cycles, was inspected at various loading frequencies to reveal the presence of any subsurface flaws. This pipe was then subjected to a series of damaging fatigue cycles and reinspected using TSA. By repeating this process information about the damage evolution has been revealed.

\section{References}

1. Dulieu-Barton, J.M. and Stanley, P., J. of Strain Analysis, vol. 33, 93-104, 1998.

2. Stanley, P. and Chan, W. K., J. of Strain Analysis, vol. 20, 129-137, 1985.

3. Sathon, N. and Dulieu-Barton, Key Eng. Matls., vols. 293 - 294, 279-286, 2005.

4. Quinn, S., Tatum, P.J., Dulieu-Barton, J.M. and Eaton-Evans, J., In Proceedings of SEM Annual Conference and Exposition on Experimental and Applied Mechanics, Saint Louis, 2006, Paper Reference 288 [10pp on CD]. 